This is the version of the article accepted for publication in International Review of Financial Analysis published by Elsevier: https://www.journals.elsevier.com/international-review-of-financial-analysis

Published under a CC-BY-NC-ND license. https://creativecommons.org/licenses/by-nc-nd/3.0/

Accepted version downloaded from SOAS Research Online: http://eprints.soas.ac.uk/26414

\title{
Playing with your Future: Who Gambles in Defined-Contribution Pension Plans?
}

\section{Gordon L Clark ${ }^{* \#}$, Maurizio Fiaschetti ${ }^{\S^{*}}$, Peter Tufano ${ }^{+}$and Michael Viehs*}

${ }^{*}$ Smith School of Enterprise and Environment, University of Oxford, Hinshelwood, Road, Oxford OX1 3QY, UK; § Department of Financial and Management Studies - SOAS, University of London, Thornhaugh Street, Russell Square, London WC1H OXG UK; "Department of Banking and Finance, Monash University, Caulfield VIC 3145, Australia. +'Saïd Business School, Park End Street, Oxford OX1 2BS, UK.

Keywords. VolATILITY, RETAIL INVESTORS, EFFECT OF EXPERIENCE, FINANCIAL DECISION-MAKING,RETIREMENT JEL Codes. G12, G41, J26, C38

Abstract. In this article, we investigate the relationship between volatility in the stock market and the trading behaviour of employees in defined-contribution (DC) pension schemes. We found that 10 per cent of our sample exhibited compulsive gambling behaviour; in other words, they both 'fed' and 'fed-off' volatility, and that their individual attributes such as gender, experience in the firm and age clearly influenced their trading behaviour. Our findings shed new light on the behavioural drivers of financial decision-making in a saving-for-retirement setting, and on the crucial importance of the need for the financial industry and policy makers to address the growing onus put on ill-equipped non-professional financial decision makers.

Acknowledgements. The authors would like to acknowledge the following bodies for funding the research: John Fell - Advanced Analytics Platform for Behavioural Finance Research of Pension Decisions (ACD03560) and CSIRO, Superannuation (LD0001 S9138). 


\section{Introduction}

Who trades in the stock market? Why? What is the relative importance of investor types and what is the nature of their relationship with volatility? The most recent academic research in finance and behavioural economics considers these questions to be of core importance, yet they are still far from being fully answered. In this article, we explore the idea that, in a saving-for-retirement setting, certain retail investors behave as noise traders and gamble in what is, for them at least, a casino-like environment. Of the issues unresolved in the literature on noise trading, two stand out as particularly relevant - the characterization and relative importance of gamblers compared with other similarly-placed individuals, and the extent to which they 'feed' and 'feed-off' market volatility to satisfy their need for risk-based excitement (Shleifer and Summers 1990).

Several articles highlight the importance of behavioural and psychological drivers in pension decision-making. For instance, Lusardi and Mitchell (2011) deal with the effect of financial literacy on retirement planning, and some very recent research supported by improved techniques of neuroimaging, such as that of Alemanni and Lucarelli (2017), look at the role that psychophysiology plays in the demand for voluntary integrative pension schemes. Nonetheless, very little research addresses the role of gambling attitudes in the context of saving for retirement. In an ageing society, when most welfare systems are shifting from 'defined benefit' to 'defined contribution' plans, we cannot neglect overtrading and its effect on the volatility of stock market returns. Given the relative and absolute importance of the trading activity that comes from this sector of the financial industry, overtrading can pose a threat to both the pension-plan participants ${ }^{1}$ who, though ill-equipped (de Dreu and Bikker 2012), are supposed to make financial decisions in their best interest, and the economic system as a whole. 
The contribution of this article to the literature on investor behaviour and market volatility contains several novel elements. For a start, we utilize an innovative way of defining gamblers and non-gamblers based on realized market behaviour rather than on an 'a priori' classification. Here, we go beyond the analogy and seek to employ certain markers of behaviour that are consistent with being a compulsive gambler to identify trading as gambling. As such, we match findings from cognitive psychology on compulsive behaviour with observed patterns of investment behaviour in a DC pension plan environment. Our approach resonates with that of Barberis et al. (1998) and others who suggest that psychological predisposition could be a crucial factor in understanding the persistence of distinct types of traders in financial markets. We can reproduce the standard results on the role of personal characteristics in driving a gambling attitude, but, unlike the other such studies, which rely on university students as test subjects, we are also able to address the importance of new subjects, such as the senior members of staff occupying permanent positions in financial firms.

Moreover, we test for gambling attitudes in a saving-for-retirement framework in which the long-term horizon for investments, along with a natural tendency towards inertia and procrastination (Clark et al. 2014), is supposed to reduce the probability of such behaviour. Our results show that pension-plan participants can be noise traders who sometimes show gambling-like behaviour. We quantify the overall incidence of this behavioural pattern and provide empirical evidence to show that gamblers, among others, lead the action in the market. We then proceed to provide evidence of the dynamics of volatility feedback: in other words, traders produce volatility, but increased volatility draws in a non-negligible share of them. Finally, focusing on the behavioural drivers of the investors, we confirm the 
importance of gender and age, and address the new effects associated with increased technical skill (linked to the period of permanence in the scheme) and seniority in the firm.

We have organized the remainder of the article into the following sections: in the literature review (section 2) we look at the behavioural literature on investment decisionmaking; we set out our research hypotheses (section 3); then (in section 4) describe our data, methods and models; depict the results of the analysis (section 5); and finally (in section 6) set out our conclusions and frame the implications of our findings for the financial industry and for policy makers. As complementary material, there are two on-line appendices: Appendix A contains a complete set of the tables and figures derived from the results of our empirical analysis, including those that we present in this article, whereas Appendix B provides a deeper insight into the type of trades and market trends.

\section{Literature review}

There are two established results acknowledged in the standard literature of finance: (1) that a relationship exists between retail trading and volatility, and (2) that gambling attitudes affect investment decision-making (Blau et al. 2016; Foucault et al. 2011; and Kumar 2009). However, the inverse relationship is less clear cut. In other words, we know very little about how volatility affects investors, particularly those who exhibit gambling-like behaviour and especially in the context of retirement planning.

As De Long et al. (1989) and others have intimated, a class of individual investors may well be inveterate gamblers: they are drawn to financial markets by the opportunity to take risks, go through phases of euphoria and pessimism, and are less concerned about fundamental value than they are about beating the market. These people may or may not have domain-specific experience and skills - such attributes are less likely deployed for 
effect than they are used to justify or legitimate risk taking for its own sake - and they are also less likely than other similarly-skilled individuals or firms to self-regulate their behaviour. Consequently, there could be three kinds of traders - noise traders who are out of their depth; savvy investors who trade on fundamentals but whom the actions of others can draw into episodes of 'over-trading'; and gamblers who are in the market for the 'thrill of it' rather than for a desired result. The issue, however, is who are these gamblers? How important are they in relation to other kinds of market players? And what drives their expectations?

Scholars have come up with various explanations for differences in investor sentiments. Some believe that rational traders are likely to be well-informed and sophisticated, but noise traders poorly informed and prone to behavioural biases and anomalies, which makes market sentiment a product of investor focus (for example market prices), information and the consistency of investment decision-making (Mendel and Shleifer 2012).

Not every investor is, however, a noise trader - many do not trade at all; some are quite sophisticated (Clark et al. 2012); and others are gamblers who, not content with the status quo, trade, trade again, and trade yet again well beyond the frequency of the average player. We assume that many people are predisposed to gamble, that is they take a chance when the probability of gain is small and the likelihood of loss is large (Kumar 2009).

Cognitive predisposition is, then, another reason for heterogeneity in the market participants' behaviour. There is evidence to suggest that flashes of overconfidence and moments of pessimism can make some people prone to errors of judgement. Scheinkman (2014), for example, postulates that the cognitive predispositions of two types of traders optimists and pessimists - can explain the existence of 'heterogeneous beliefs'. In this respect, some people might always be either optimists or pessimists. Alternatively, others 
might oscillate between the two states, thus reinforcing expectations of success without reference to the evidence in a rising market and expectations of poor performance despite the evidence in a declining market. This type of behaviour is consistent with herding and market following based on expectation formation over time, which in effect is recognizing that framing, myopia and status quo bias render many people prone to errors of judgement (Baron 2012).

Apart from errors of judgement and/or a cognitive predisposition, behavioural psychologists suggest that experience and skill can affect the decision-making performances of individuals. Insofar as experience translates into learning-by-doing, so prompting the recalibration of expectations, some people seem able to transcend the errors due to myopia and status quo bias by employing Bayesian analysis rather than following market sentiment - these are the people whom Mendel and Shleifer (2012: 303) call 'insiders'. Skill can also make a difference, especially if it is domain specific. Indeed, with the appropriate skills, individuals can use experience in ways that reinforce their advantages over noise traders and 'outsiders'. Tests of decision-making competence, comparing undergraduates with investment professionals in terms of their abilities to solve problems akin to those the participants in financial markets face, suggests that skill and experience are important distinguishing attributes of individual performance (Clark et al. 2006).

In this article, we are concerned with the determinants of compulsive behaviour in a UK DC pension plan and, as such, consider the frequency and timing of investment behaviour. The premise underpinning our research is that compulsive behaviour is indicative of a predisposition to gamble and not just to respond to market sentiment. In this section, we aim to reach a twofold goal. First, relying on recent research in cognitive science, we want to point out the difference between taking a risk and gambling. Second, given the 
importance of considering variations in the behaviours of diverse types of market players, we explain why we might expect age, gender and income to make a difference.

Anecdotal evidence suggests that many people associate taking a risk with gambling, a link that most recent academic literature confirms. Doran et al. (2012), for example, show how the gambling preferences of investors affect the prices and returns of the specific assets that have lottery features. Consistent with prospect theory, the main findings of Kirchler et al. (2005) indicate a strong framing effect in decision-making involving risk taking. Weber et al. (2013), on the other hand, show how subjective judgements and emotional factors rather than quantitative estimates are key drivers of changes in risk taking; Cain and Peel (2004), on their part, provide an insight into the utility of gambling and analytically justify the phenomenon of the favourite-longshot bias.

Three implications arise: first, there are situations in which taking a risk is the same as gambling. Second, if the action entails skill and experience and carries a reward, then taking a risk is not the same as gambling. Third, people with knowledge and understanding of the circumstances may be in a better position to take a risk than their less privileged counterparts. For them, the game may be more about risk assessment than gambling, whereas for others it may be more about gambling than risk taking. By this logic, we can define risk taking as an activity in which the player considers the existing information and understands the situation, including the possible payoffs associated with the various available strategies. To gamble is, conversely, on the roll-of-a-dice to bet in circumstances in which skill and experience are irrelevant to the outcome and in which all parties have an equal chance of success. ${ }^{2}$

By this account, gambling would appear to be a cognitive rather than a sociodemographic problem. However, there is evidence that men rather than women tend to 
gamble, and that men feel more confident making decisions in situations that involve chance. Bolla et al. (2004) showed that men process risk taking in diverse ways and are more adept at playing games of chance. Knowing that they are good at games of chance may tempt them to play them, whereas women may seek to avoid such situations. There is also evidence that children tend to perform worse than adults in the lowa gambling task $(\mathrm{IGT}),{ }^{3}$ and that older adults tend to outperform younger ones, perhaps because they are better at taking advantage of experience (Carvalho et al. 2012). Kumar's (2009) study of stock-market gambling began with state lotteries, for which there is no reward for having any knowledge or understanding of how to play the game. Observing that those who play lotteries tend to be poor, young, poorly-educated single men who live in urban areas and belong to minority groups, he found that these same characteristics were associated with 'greater investments in lottery-type stocks' (Kumar 2009: 1891). Another approach to the issue is through cognitive science and the psychology of decision-making under conditions of risk and uncertainty.

In the IGT, gambling involves playing the game for its own sake rather than governing one's behaviour in relation to the underlying structure of rewards and losses. In this respect, to gamble is to deny the benefits of experiential learning. The issue is self-control, namely whether one can balance the excitement that comes with gambling against the consequences of taking large and small bets.

One characteristic of compulsive gamblers is the frequency of their betting behaviour, but the evidence about whether a positive or negative result affects the frequency is mixed. Linnet et al. (2010) suggest that loss-chasing is an indicator of compulsive behaviour in that those involved play the game for the excitement rather than the reward. According to $\mathrm{Yu}$ and Zhou (2006), however, some people make riskier choices following an unexpected win; 
in other words, their behaviour is not really about winning but about risk taking when, in a psychological sense, a win justifies placing a larger bet. Furthermore, it appears that gamblers gamble for longer whatever the risk and reward payoff matrix, perhaps because of impaired dopamine, which dampens the psychic effect of any single action (Riba et al. 2008). Finally, in common with other forms of self-abuse such as alcohol and drug consumption, there is evidence that gambling is compulsive and addictive (Tanabe et al. 2007).

\section{Research hypotheses}

By matching recent research in cognitive science with that on retail investors and volatility, it is possible to put forward a series of research hypotheses on the expected nature, prevalence and general effects of gambling on DC pension schemes and the effect of such behaviour on stock market volatility.

A compulsive gambler is, by definition, less constrained by risk and reward than someone who gambles occasionally. The evidence suggests that younger men are more likely to gamble than older men, and that men are more likely to be successful gamblers than women, particularly in the initial stages of a gambling episode. Age, gender, family circumstances and income are correlated with the propensity to gamble more than normal, but the efficacy of socio-economic characteristics driving a gambling attitude is not immediately obvious (cf. Kumar 2009: 1890). Studies on compulsive behaviour in the fields of cognitive science and psychology reveal several crucial insights, or predictions, about patterns of gambling over time. These insights underwrite the empirical logic of our article. For example, compulsive gamblers: 
- seek out environments in which they can express their predisposition to take risks, hence they prefer a volatile stock market over one with low volatility;

- act sequentially, stringing together successive bets until something stops them, which means that the interval between successive bets is small and can shrink over time;

- value risk taking rather than calibrating risk and reward, thus negating the need for a relationship between actions taken and their consequences; and

- are more likely to be men than women, are younger rather than older adults, and are more likely to lose than win in games of chance over a sequence of bets.

The distinction between taking a risk and gambling becomes particularly important when, at first sight, it might look as if the object of analysis concerns one action rather than a string of related ones. Hence, we are especially interested in identifying individuals who make successive, as opposed to one or two, bets before they stop. The findings of cognitive science and psychology are consistent with distinguishing between high and low frequencies of trading and they provide us with a means of classifying, if not categorically distinguishing between, risk-taking behaviour within a DC saving and investment environment. They also give us an opportunity to match the initiation of trading with compulsive behaviour and changes in the stock market environment. In other words, we expect market volatility to prompt thrill-seekers to enter the market via their DC savings accounts.

Overall, one can draw four distinct research hypotheses with the correspondent testable implications:

Hypothesis 1 (H1): some pension-plan participants are noisy traders and some of these show a gambling-like behavioural pattern. 
Hypothesis $2(\mathrm{H} 2)$ : participants produce and feed off volatility in what we deem to be a bidirectional relationship.

Hypothesis $3(H 3)$ : market players who show a gambling-like behavioural pattern mainly determine the relationship between volatility and trading activity.

Hypothesis $4(\mathrm{H} 4)$ : since socioeconomic and personal characteristics and their interactions are what determine gambling-like behaviour, a longer time horizon and saving-forretirement decision-making framework have no effect on the socioeconomic drivers of gambling behaviour in the context of a standard investor problem.

\section{Data, methods and models}

\subsection{Data and sample scheme}

Mercer (UK) and its human resources consulting (HRC) branch supplied the data on individual behaviour in the DC environment. ${ }^{4}$ This firm provides advisory services to private and public entities, as well as to the managers of defined-contribution (DC) and definedbenefit (DB) pension schemes.Our initial database included the personal details and transaction records of 17,690 people ('participants') across 19 pension schemes, which were tracked from 2002 to 2012 . As Table I (a) shows, the spread of participants and transactions between the schemes is uneven, with 52 per cent of the platform population and 60 per cent of transactions concentrated in three (non-overlapping) schemes. Mercer provided the data in separate files with a unique identifier available only at a scheme level. The meagreness of the information on the participants and their employers made it impossible to quantify the risk of observations overlapping across schemes, so we decided to present our empirical analysis in two stages. In the first, we analysed (i) the whole database with all 
the schemes pooled together; (ii) the three most representative schemes (BBB, $\mathrm{HHH}$ and $\mathrm{MMM}$ ), comprising roughly 52 per cent of the overall data, pooled together and henceforth named macro-scheme; and (iii) each scheme singularly. We could thus exploit the full potential of the information in the database and control for the possible risk of overlapping observations. In this article, we present the results for the whole database, for the macroscheme, and for the most representative scheme 'MMM' (henceforth 'sample scheme'). All the other results are available in our online Appendix A. When, in the second stage of our analysis, we turn our attention to the behavioural drivers of compulsive gambling, the structure of the data forces us to focus the analysis on the sample scheme - the algorithm of estimation failed to converge on any plausible solution with the other representative schemes and different sorts of aggregations. Nevertheless, the sample scheme is the largest one and it accounts for roughly 27 per cent of the active participants and 21 per cent of the transactions.

\section{[Insert Table I About Here]}

In terms of activity, 59.21 per cent of the participants in the sample scheme (or 1,993 individuals) made at least one transaction over the period; the remaining 40 per cent, possibly exhibiting Samuelson and Zeckhauser's (1988) status quo bias, were not active in any way. For the behavioural analysis, we chose to focus only on the sample scheme, for the low number of active participants in other schemes not only makes it difficult to reach convergence in the algorithms of estimation but also undermines the reliability and robustness of the results. This does not apply to the analysis of frequency and volatility, where the higher number of participants involved and the focus on quantitative rather than qualitative drivers makes the risk of potential bias less harmful. In our view, this empirical 
strategy is optimal if we are to exploit the full potential of the information in the database yet ensure a sufficient level of reliability and robustness of the analysis.

A simple recognition of its characteristics shows how the data base has a fairly good gender balance (Table II (a)) with a slight majority of men (61.68 per cent for the pooled sample and 54.78 per cent for the sample scheme). The average investor enters the scheme at a relatively young age ( 35 and 31 years respectively), has on average been in it for a considerable length of time (22 and 29 years respectively), but on average has less experience with the firm in question ( 7 and 12 years).

\section{[Insert Table II About Here]}

Since a gambler is somebody who is unable to resist the urge to gamble, we divided our sample into two drivers - number of transactions and their frequency. We recorded the number of dealings each person made and noted the number of months (elapsed time) between two successive transactions. We then defined the frequency of transactions as the inverse of the elapsed time (frequency $=1$ /elapsed time) and divided both the distributions of the number of transactions and their frequency into quartiles. Finally, we focused on the upper and lower quartile of each distribution and, through observing their combination, identified three behavioural patterns among the participants:

- 'quiet': lower quartile for number of transactions and frequency;

- 'mixed': lower quartile for number of transaction and higher for frequency or vice versa;

- 'gamblers': upper quartile for both number and frequency of transactions.

Table II (b) shows the distribution of these types of participants across the schemes in absolute and percentage terms. Some 30.15 per cent of those in the pooled database fitted 
the mixed category, 3.55 per cent were in the quiet category and an estimated 8.80 per cent were gamblers. These results are consistent with those of the sample scheme in which the mixed, quiet and gambler participants accounted for 36.79, 10.90 and 11.49 per cent respectively.

Since compulsive gamblers tend to lack control in the presence of risk and reward, we also sought to determine whether increasing market volatility affected (or even prompted) changes in the volume of transactions and their frequency. Figure 1 displays the monthly market volatility (high and low) of the FTSE 100 index over the period between 2002 and 2012, along with the responses of the new active participants for both the macro and sample schemes. A visual inspection suggests a lagged positive relationship for both, which therefore makes it a subject for further investigation. One should also note that the macro scheme registered abnormal dynamics in the year between February 2010 and February 2011: a closer inspection of the figures, however, suggests that this might be attributable to a company action, such as restructuring the schemes.

\section{[Insert Figure 1 About Here]}

\subsection{Gamblers: a robustness check}

The correct identification of gamblers is central to the paper. We, therefore performed a robustness check of this behavioural pattern, as defined in the previous section, based on two issues: the characteristics of the trades coming from gamblers and their activity during periods of up and down trend in the market. We aimed to show how the behaviour of those we labelled 'gamblers' is consistent with the expectations of the standard literature on gambling. In particular, we focused on two characteristics - the tendency to increase their commitment during downtrends (the gambler's ruin) and the scant attention to standard 
risk considerations. The results were encouraging (see the online Appendix B for further details): we found an increase of 10 per cent in the trading from gamblers in periods of downtrend with respect to period of uptrends, signalling the 'gamblers' ruin' behaviour. Moreover, we found that the clear majority of the operations done by gamblers consisted of switching between two funds with the same risk profile (44.83 per cent), thus suggesting a need to act rather than a true portfolio rebalancing. Finally, we found that, when looking specifically to the switching operations coming from gamblers (in the representative scheme), the tendency to increase the activity during periods of downtrend is confirmed and its magnitude is even bigger. The encouraging results confirmed the robustness of our identification procedure and led us to go on with our empirical analysis of the correlation between gambling attitude and volatility.

\subsection{Models and testable implications}

As mentioned earlier, we present our empirical analysis in two stages. In the first, we investigate the actions of participants to establish whether there is any relationship between volatility in the stock market and the role of those showing a gambling-like behavioural pattern. Then, in the second, to understand the drivers behind their activities, we examine the association between the participants' trading behaviour and their personal and socio-economic characteristics.

Focusing on hypotheses $\mathrm{H} 1$ and $\mathrm{H} 2$, we test for the existence of a positive and statistically significant correlation between the number of participants each month making their first transaction (henceforth new active participants) and the volatility of the stock market. Like Foucault et al. (2011), we first use a sample, but unlike them, we want to assess the inverse 
relationship between retail activity and volatility. Consequently, we use a simple OLS with the following specification:

$$
T A_{t}=\beta_{0}+\beta_{1} V+\varepsilon_{t} \quad[\text { Equation 1] }
$$

where $T A_{t}$ is the number of new active participants in that month (time $\mathrm{t}$ ), as a proxy for the trading activity. Like Foucault et al. (2011), we too are aware of the endogeneity between the dependent and independent variables and that this can bias the estimation, but it also has two main advantages. It is a useful starting point for further analysis and it allows us to switch the dependent and independent variable to focus on the feedback of volatility, which is our real angle of interest. As a further step in the analysis, looking at monthly lags of up to six months, we calculate a correlation matrix between the new active participants and market volatility and we do the same for the returns. The reason for choosing to investigate the importance of lagged volatility and returns lies in the cognitive research: compulsive gamblers look for excitement, so they play repeatedly, irrespective of the payoff structure. In a market setting, this means being 'drawn into' a casino-like environment, with little (if any) role given to the returns. As in the IGT, the player, potentially a compulsive gambler, 'learns' about the environment and reacts, which implies a link with a realized condition of the market (namely lagged volatility and returns).

Hypothesis $\mathrm{H} 3$ looks at the leading role of gamblers in driving trading activity, which one can translate into their behaviour being the most likely explanation for the variability of the database. To test this implication, we performed a principal component analysis (PCA) based on the three behavioural patterns of trading defined in the previous section - quiet participants, mixed participants and gamblers. To perform the PCA we make the standard assumptions that: 
- the three types of participants describe the whole database (linearity);

- mean and variance have a primary (sufficient in statistical terms) role in defining the characteristics of the database (mean and covariance); and

- large rather than small variances are important (large variance).

As a further test, we run an interquantile regression with the following specification:

$$
\stackrel{P}{P}=\beta_{0}+\beta_{1} L V+\varepsilon_{t} \quad \text { [Equation 2] }
$$

where IQR is the interquantile range at time $t$, defined as the difference between the ninetieth and tenth percentile of the distribution of the monthly number of new active participants and $\beta_{0} L V$ is the lagged volatility in the stock market at time t. Compulsive gambling is an 'extreme' trading behaviour that the potentiality of high gains and losses triggers. As such, we would expect lagged volatility to lead not only the trading activity, but also its 'polarization', that is the increased distance between upper and lower extreme forms of behaviour, which are supposed to react in an opposite way to changed market conditions.

We then try to establish who is leading the trading activity: to do this, we estimate the correlation between the monthly number of new active participants and the lagged volatility for each of three behavioural patterns - gambler, mixed and quiet. As for $\mathrm{H} 1$ we use a simple OLS with the following specification:

$$
T A_{j t}=\beta_{0 j}+\beta_{1 j} V+\varepsilon_{j t} \vartheta=1,2,3 \quad \text { [Equation 3] }
$$

where $T A_{j t}$ is the trading activity at time $t$ for the ofype of participant and equeal to 1 when the participant is 'quiet', 2 when it is 'mixed' and 3 when it is a 'gambler'. Finally, we 
turn our attention to hypothesis H4 to address the role of 'contextual' (Simon 1956) variables in driving gambling behaviour. To exploit fully the heterogeneity of trading behavioural patterns, and to increase the efficiency of the estimation, we give further attention to the types of participants. Our primary purpose is to decrease variability within, but to increase it between, the groups, to eradicate as much statistical (and behavioural) noise as possible. We then combined the quartiles of the number and frequency of the active participants' transactions (the reciprocal of the time between two consecutive transactions), which yielded the following five types of participant:

- 'dormant': up to one transaction in the whole period;

- 'quiet': few transactions at low frequency;

- 'emotional': few transactions with high frequency;

- 'steady': many transactions and low frequency; and

- 'gamblers': many transactions and high frequency.

We then focused on the effect of the participants' socio-economic and personal characteristics on the probability of them belonging to each of the five types and behaving accordingly. To do this, and in keeping with the nature of the data, we chose to estimate a multinomial logit model with the following general formulation:

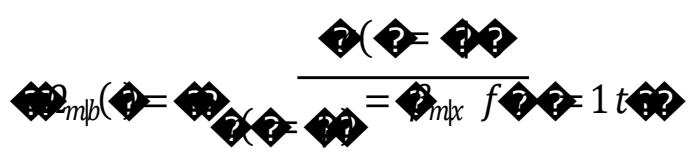

where $b$ is the base category (reference group) that acts as a benchmark to assess the logprobability of all the others and $\mathrm{x}$ is a vector of covariates, which, in our case, is made up of age, gender, experience in the scheme (number of years), experience in the company 
(number of years), average transaction value (f), fund chosen within the scheme and fixed effects for the calendar year. We chose the largest one (the dormant participants) as the base category because this is standard practice and because, given the structural characteristics of this model, the results are not going to change with a different choice. It is possible to solve the general formulation to obtain the J-1 equations of the predicted probabilities of belonging to the correspondent J-1 categories:

$$
\gamma(2)=\frac{\exp \left(x \beta_{m \mid b}\right)}{\sum_{j=1}^{J} \exp \left(x \beta_{j \mid b}\right)} \quad \text { [Equation 4] }
$$

In our case, we have five categories $(m=5)$ and we estimate 4 equations for the predicted probabilities. We present and discuss the results of our empirical analysis in the following section.

\section{Results}

We start testing the correlation between the number of the new active participants and the volatility in the stock market. Table III (a) shows the correlation coefficients for the sample scheme and the first six lags of the volatility.

\section{[Insert Table III About Here]}

As expected, we only found significant relationships for lagged values (lag 1, 2 and 6); we see this as a sign that a group of DC plan participants sought out opportunities to express their gambling instincts. The result holds across the schemes and the estimation of Equation 1 for the database confirms the absence of any correlation by or for either the macro or sample schemes (Table III (b)). The correlation matrix between the number of new active participants and the returns provides a weaker and less stable relationship across the 
schemes (see online Appendix A for the full range of results). Hypotheses $\mathrm{H} 1$ and $\mathrm{H} 2$ are, then, confirmed as transacting in a market environment characterized by volatility, which is evidence of excitement-seeking with no clear link to the returns. The relationship between market volatility and trading activity could, however, be more complex than expected.

Drawing from Hypothesis 3, we focus on which type of participant (if any) is leading the trading activity. Table IV shows the results of a principal component analysis (PCA) aimed at investigating which is the most representative component (type of trader) for the whole database, for the macro-scheme and for the sample scheme respectively. The PCA reorganizes the database around its components and points out how many and which among them are best suited to 'lead', that is they are statistically sufficient to represent the variability of the database itself. We chose components that presented an eigenvalue of the covariance matrix higher than 1.

\section{[Insert Table IV About Here]}

As Table IV shows, gamblers are always the most meaningful component; they have a value of 1.6723 for the whole database, of 1.8057 for the macro-scheme and of 1.6596 for the sample scheme; the same holds true across all the schemes singularly (see online Appendix A). The column headed 'Proportion' shows the share of information 'explained' by the correspondent component: according to our analysis, gamblers alone account for 55.74 per cent, 60.19 per cent and 55.32 per cent of the overall variability of trading activity. They literally lead the group's activity, thus confirming our expectations on Hypothesis 3 . We investigate this bidirectional relationship further by turning our attention to Equations 2 and 3. First, to check if the role of new active participants can explain the activity spread, we 
estimate the relationship between the interquantile range of their number and the lagged volatility.

\section{[Insert Table V About Here]}

Table $\mathrm{V}$ (a) contains the results for the whole database, as well as for the macro and sample schemes: when pooled together, the schemes fail to show a significant relationship, but at a scheme level most do (see online Appendix A). The estimation of Equation 3, namely how well the lagged volatility explains the activity of each type of participant, helps us to understanding better the nature of the relationship. As Table $\mathrm{V}$ (b) shows, $\mathrm{a}$ relationship does exist between a specific type of trader and lagged volatility, but for the most representative scheme it only holds for the gamblers.

What drives the gamblers' behaviour in a saving-for-retirement framework? Do investor gamblers behave differently in a more standard environment? We estimate [Equation 4] to answer this type of question. As personal characteristics, we use the age of the participants on joining the scheme and their gender, whereas experience in the scheme and firm are, respectively, proxies for both improving skills in managing the technicalities of making transactions and for the peer effect (intended as increasing exposure to the average behaviour). We added yearly fixed effects to capture common time trends and standard errors. Finally, testing for multicollinearity, we estimated the variance inflation factor (VIF). Its maximum value of 3.49 for the yearly controls suggests that the level is acceptable, and that multicollinearity is not an issue (Chatterjee et al. 2000).

Table VI shows the marginal effects for each variable at the mean values of all the others, as well as the predicted probabilities in each behavioural pattern. We display these probabilities in the first row of each category of outcome and are close to the actual 
correspondent sample shares (the extremes are easier to capture). Dormant trading is the single most likely outcome, conditioned to the mean value of the explanatory variables, with a predicted probability of 78.93 per cent, whereas compulsive gamblers have a 9.83 per cent chance.

\section{[Insert Table VI About Here]}

In general, age at enrolment is a significant factor in two of the five behavioural patterns (the marginal ones). Similarly, gender is statistically significant for marginal behaviour and for those identified as 'emotional' participants, whereas the average size of transaction adds a significant factor to the 'steady' participants. Our proxies for skill and the exposure effect are relevant in triggering emotional and compulsive gambling behaviour; this may indicate that exposure to 'average behaviour' in a plan only affects behaviour at the margin (cf. Beshears et al. 2015).

Focusing on the latter pattern, our results show how the direction and magnitude of the marginal effects are consistent with our expectations. Gender is very important in driving compulsive gambling: being male increases the likelihood of gambling behaviour by 17.58 per cent and is the single most crucial factor. The size of the bet (average transaction value), though statistically significant, has a relatively small effect, thereby confirming the experimental evidence suggesting that an individual's background characteristics condition this effect (Clark et al. 2009). On the other hand, stage in the life cycle affects the probability of compulsive gambling; it is significant at 10 per cent and with a small effect $(0.20$ per cent): an increase in the age at enrolment increases the likelihood of acting compulsively. In the light of the life-cycle hypothesis, enrolling one year later could proxy a built-in wealth effect, thus exerting a positive influence on acting compulsively. By contrast, the role that 
experience plays in both the scheme and the company is highly significant and nonnegligible. The two effects are similar in magnitude but point in opposite directions. Longer experience in the scheme increases the probability of overconfidence and hyperactivity (+1.27 per cent), whereas prolonged exposure to average behaviour (experience in the company) acts in the opposite way by smoothing the dynamics of marginal outcomes $(-1.29$ per cent). The interaction between these two competing forces is worthy of deeper insight and is best performed graphically.

As shown in Figure 2 (a) to (d), we focus on experience in the company and in the scheme, but also provide insights into the role of life cycle and average transaction value.

\section{[Insert Figure 2 About Here]}

According to our results, gender mediates the interaction between the life cycle effect and average transaction value (Figure $2(a)$ ): the higher the transaction value, the weaker the effect of age at enrolment, but the flatter slope of the highest average transaction value suggests a curbing of the gender effect when the stakes are relevant. Figure 2 (b), by contrast, shows the interaction effect between experience in the scheme and average transaction value. Here, the dispersion among the various categories of average transaction value is higher; again, relevant stakes dampen the interaction effect, which gender only weakly mediates. Figure 2 (c) shows the interaction effect between life cycle and increased skill. Gender mediates the interaction effect, which is higher for men. Women, on the other hand, have a more homogeneous response, but men have a higher dispersion in response across age cohorts. Finally, Figure 2 (d) shows that the interaction between experience in the scheme and in the company draws a slightly more complex picture of the average effect assessed in the analysis of the margins. Here, prolonged exposure to the same working 
environment completely offsets the positive effect of higher skills in being a compulsive gambler. When the exposure effect is lower, increased skill effects response, which is remarkably higher for men than for women. By contrast, when experience in the company is lower, the slope flattens to exhibit a weakening of the gender effect. Nonetheless, the relative magnitude is reversed: the effect is higher for women than for men. In other words, when not dampened by prolonged exposure to average behaviour, the effect of increased technical confidence is higher for women than men. We interpret this result as a 'catch-up effect' for women who start from lower levels of self-confidence. The results of our multinomial logit analysis are consistent with those of the standard literature on investor behaviour. This then verifies Hypothesis $\mathrm{H} 4$, with the implication that it is not possible to make the case for a specificity of the behavioural drivers of the decision-making process of investors acting in a saving-for-retirement framework. Policy makers should focus on what technically makes an investment problem in a retirement framework different from an investment problem in a standard framework - for example, longer time horizons, the risk of longevity, or the co-called annuity puzzle.

Our study identified about 10 per cent of UK DC plan participants as compulsive gamblers. Given the findings of cognitive science and psychology, which commonly report that about 5 per cent of tested subjects are compulsive gamblers, this seems a large number. Although our sample scheme is representative of the schemes that Mercer (UK) administers, it may not be representative of the population at large. Nonetheless, given the distinctive nature of laboratory-based testing, the characteristics of test subjects (who are often undergraduate or graduate students), and the artificial circumstances in which test subjects perform, compulsive gambling could be higher in environments such as financial markets than hitherto assumed (Shiller 2005). 
It is known that the probability of being a compulsive gambler is gender-related and that men are more likely than women to be compulsive gamblers. Among those labelled as compulsive gamblers, the distribution of men is more compact (homogeneous) than that of women (heterogeneous) - men are men (Barber and Odean 2001), whereas women are sometimes like men but otherwise not like men.

Life cycle also plays a role; this matches similar findings in cognitive science and psychology where the effect of age is inconsistent (comparing young people with middleaged people and with much older people): enrolling one year later increases the probability of acting compulsively by revealing what we interpret as a proxy for a built-in wealth effect easing compulsive behaviour. Conversely, the average value of a transaction, though statistically significant, has a small effect on the probability of being a compulsive gambler. Here, the higher the average value of a transaction, the lower the likelihood of the person concerned being a gambler. There are several possible interpretations for this result. For example, investors could be playing the game, that is transacting in a volatile market, for the excitement, but subject to self-imposed limits on the value of any transaction in a sequence of transactions. Another interpretation might be that, in seeking excitement, compulsive gamblers intuitively recognize that the 'cost of playing the game' is to put in play some portion of their account. In other words, they use their DC account like pin money in a card game. That participants tend not to gamble on large-value transactions is less important than the pattern of transacting in relationship to market volatility.

There is considerable interest in whether peer effects are important for individual savings' behaviour (Beshears et al. 2015). The cognitive science and psychology literature, however, holds that learning from others is always less significant than learning from the consequences of one's own behaviour (Yu and Zhou 2006). In this respect, and focusing on 
the interaction between experience in the scheme (years of trading) and in the firm (years of service), we found that the former increases the probability of being a compulsive gambler, whereas the latter completely offsets that effect.

Overall, as the literature on overconfidence confirms, being male increases the effect of experience in the scheme and the value of the transaction on the probability of being a compulsive gambler. Conversely, there is a positive association between being a woman and taking the value of the transaction into account when gambling. This is consistent with women being more cautious than men even if they are drawn to the excitement of gambling, which is widely noted in the psychology and behavioural literature. ${ }^{5}$ There is one exception to the association between gender and increased skill and this is when seniority in the company is low. In this case, being more skilled has a bigger effect on women than men, possibly signalling a catch-up effect on self-confidence.

It is important to note, however, that the gender effect fades with age. In our sample, in relation to their propensity to gamble, men and women tend to behave more like one another as they get older. In other words, both older men and older women are less likely to be compulsive gamblers. At one level, this is a pleasing result. As men and women age, the prospect of retirement looms larger and their welfare in retirement is more salient. As suggested elsewhere, 'salience' is a key issue when people come to plan for their retirement (Clark et al. 2012). The implication is entirely straightforward: the costs and consequences of being a compulsive gambler are more obvious at an older age, when retirement is the relevant consideration. At another level, this is not an entirely encouraging result because some younger people, mostly men but also some women, value excitement over a remote future state of being, which they can only observe in others rather than directly experience themselves. Either way, they are myopic (Becker and Murphy 1988; Laibson 2003). 


\section{Conclusions and policy implications}

Many people gamble without threatening their long-term well-being. To gamble is to take a risk rather than make a calculated decision informed by knowledge and understanding of the payoffs of the various options. In this respect, we focused on compulsive gamblers, namely those UK DC participants who fell within the upper quartile in terms of both the number and frequency of their transactions. We also analysed behavioural patterns of trading and their determinants.

Since our aim in this article was to contribute to the academic debate on compulsive and marginal behaviour, to help the financial industry better understand the needs of its clients, and to assist policy makers, we based our study of compulsive behaviour on the supposition that individual identity is less important than cognitive predisposition. By implication, we might expect that people who gamble in a DC pension environment are a random mix of men and women, young and old, competent and incompetent. In fact, studies conducted by cognitive scientists and psychologists suggest that men tend to gamble more than women, that men are more effective gamblers than women, and that the predisposition to gamble is particular to an individual, although observing the behaviour of others can make a difference. In this respect, we found that being male with an elevated level of technical competence enhances the probability of acting compulsively. By contrast, seniority in the firm and the transaction being of a higher than average value decrease this likelihood, even although we noted a remarkable richness in the interactions among these drivers of behaviour and these findings were consistent with our expectations.

If we assume that the financial industry indeed wishes to improve the services it supplies to its clients, our research finding that compulsive gambling is commonplace in DC pension schemes, albeit not shared by the 'average' investor, might help plan managers decide what 
policies to pursue. The simplest way forward and one that honours the principle of respect for individual volition, would be to do nothing other than inform all participants of the costs and consequences of compulsive behaviour. However, given the evidence that advice facilities are under-utilized, and that there is a high degree of inertia and low financial literacy among participants, a better targeted (even tailored) service could improve the sector's overall performance, which in turn would have a positive impact on social welfare.

There are several ways in which to do this, some more effective than others. However, given that compulsive gambling involves individuals who discount self-governance, it seems unlikely that appealing to their self-interest would dampen their thirst for excitement. Another way of dealing with the issue would be through properly tailored policy measures to nudge people into a decision-making environment with structured choices that limit opportunities for compulsive gambling (Thaler and Sunstein 2008). Even if effective for the majority, it is unlikely to work for those who actively seek opportunities to gamble. Some authors have suggested channelling active participants through a series of gates and hurdles that take them into risk and return environments that require higher levels of skill and expertise (Clark and Urwin 2011). One could require those who are predisposed to be active and who seek excitement to demonstrate a level of competence consistent with the possible costs and consequences of their actions. To reinforce the screening effects of a gates-and-hurdles regime, one could place limits on a participant's initial bets that permit excitement but contain any losses. Screening devices could allow the managers of DC schemes to identify those whose behaviour may require a level of oversight wasted on the average participant. While any gates-and-hurdles regime is likely to be paternalistic, in circumstances where participating in workplace DC schemes is important for long-term wellbeing, there is a public interest in dissuading compulsive gamblers from treating pension 
investments as they would other forms of gambling. In this respect, our article contributes to the debate on finding an optimal design for policy rules to support the financial decisionmaking of those who are ill-equipped to act in their own long-term self-interest. In our estimation, roughly 10 per cent of the population engages in 'compulsive gambling behaviour': this is marginal, but not negligible. Being able to characterize the nature and magnitude of the link between personal and socio-economic drivers and making financial choices is extremely important if we are optimally to frame a system of policy rules. For instance, growing imbalances in the gender/age composition of the population, if combined with an extended period of high volatility in the stock market, could trigger semi-automatic stabilizers for long-term asset managers. To understand fully the significance of our analytical framework and the results we have obtained from it, it is necessary to take several issues into account. One is the possibility that a selection bias may be embedded in the data. If, as research on addiction and gambling suggests, an indicator of 'problem' gambling is compulsive behaviour, then it is possible that our sample inadequately represents that portion of the population for whom this problem has negatively impacted on their ability to hold down a job.

Reinforcing this issue is another concern: we have been unable to observe the background characteristics of participants who exhibit compulsive behaviour. It may be that rising incomes and house-price appreciation have more than offset the long-term costs (if there are any) of gambling on the UK stock market through one's participation in a DC pension scheme.

Finally, there is a caveat to this type of study, widely acknowledged in the field but difficult to overcome. By the age of 30 , many DC pension plan participants are in a relatively stable relationship with another person. Typically, this other person does not have the same 
employer nor, necessarily, the same kind of income and retirement benefits. While we should be cautious about attributing too much to household behaviour, some households pursue collective or joint savings strategies in which one partner pursues a more cautious approach to investment than the other. In some cases, one partner may be in a relatively low paid job, but with a high likelihood of continuity of tenure with (perhaps) a DB pension scheme, whereas the other may have a succession of highly paid jobs accompanied by DC pension benefits. In effect, one partner's high-risk DC investment strategy may appear to be consistent with compulsive gambling, but the other's low-risk saving strategy deliberately offsets it (Clark et al. 2012).

These three caveats are significant, although each is a challenge in terms of how we might design a research strategy that combines administrative databases with detailed knowledge of individuals' background circumstances and opportunities. One way forward would be to set up field experiments and test the impact of these factors. Even so, given the moral opprobrium attached to addiction, gambling and substance abuse, we doubt that this type of framework would resolve the issues as identified above.

\section{Notes}

1. In this article we use the expressions 'pension plan participants', 'investors', 'market players', 'traders' and 'employees' equivalently.

2. Stanovich (2010: 79) notes that some 'people see links between events in the past and events in the future when the two are really independent'. Pathological gamblers justify their actions to themselves and others by acting as if their beliefs are indicative of a higher level of understanding that neophytes do not share.

3. The lowa gambling task (IGT), designed to deal with patients with pre-frontal brain lesions, has become the standard test for determining who is prone to gamble. 
4. In November 2014, Mercer, a global consulting company, had more than 20,000 employees based in more than 40 countries and an excess of US\$ 108 billion in assets under management. For further details, see www.uk.mercer.com

5. See, among others, Charness and Gneezy (2012).

\section{References}

Alemanni, B. and C. Lucarelli (2017) 'Individual behaviour and long-range planning attitude', European Journal of Finance, 23 (5) 407-26.

Barber, B. and T. Odean (2001) 'Boys will be boys: gender, overconfidence, and common stock investment', Quarterly Journal of Economics, 116 (1) 261-92.

Barberis, N., A. Shleifer and R. Vishny (1998) 'A model of investor sentiment', Journal of Financial Economics, 49, 307-45.

Baron, J. (2012) 'The point of normative models in judgment and decision making', Frontiers in Psychology, special issue on 'From is to ought: the place of normative models in the study of human thought', edited by S. Elqayam and David E. Over, 7 (628) 11-13.

Becker, G. S. and K. M. Murphy (1988) 'A theory of rational addiction', Journal of Political Economy, 96 (4) 675-700.

Beshears, J., J. J. Choi, D. Laibson, B. C. Madrian and K. L. Milkman (2015) 'The effect of providing peer information on retirement savings decisions', Journal of Finance, 70 (3) 1161-1201.

Blau, B., T. Bowles and R. Whitby (2016) 'Gambling preferences, options markets, and volatility', Journal of Financial and Quantitative Analysis, 51 (2) 515-40.

Bolla, K. I., D. A. Eldrtih, J. A. Matochik and J. L. Cadet (2004) 'Sex-related differences in a gambling task and its neurological correlates', Cerebral Cortex, 14 (11) 1226-32. 
Cain, M. and D. Peel (2004) 'The utility of gambling and the favourite-longshot bias', European Journal of Finance, 10 (5) 379-90.

Carvalho, J.C., C. de Oliveira Cardoso, D. Shneider-Bakos, C. Haag Kristensen, G. Paz Charness and U. Gneezy (2012). 'Strong evidence for gender differences in risk taking' Journal of Economic Behavior \& Organization, 83: 50-58.

Charness, G. and U. Gneezy (2012) 'Strong evidence for gender differences in risk taking', Journal of Economic Behavior and Organization, 83 (1) 50-8.

Chatterjee, S., A. Hadi and B. Price (2000). Regression analysis by example. New York: Wiley.

Clark, G. L. and R. Urwin (2011) ‘DC pension fund best-practice design and governance', Benefits Quarterly, 27 (4) 39-49.

Clark, G. L., E. Caerlewy-Smith and J. C. Marshall (2006) 'Pension fund trustee competence: decision-making in problems relevant to investment practice', Journal of Pension Economics and Finance, 5 (1) 91-110.

Clark, G. L., E. Caerlewy-Smith and J. C. Marshall (2009) 'Solutions to the asset allocation problem by informed respondents: the significance of the size-of-bet and the $1 / \mathrm{N}$ heuristic', Risk Management and Insurance Review, 12 (2) 251-71.

Clark, G. L., K. Strauss and J. Knox-Hayes (2012) Saving for retirement, Oxford: Oxford University Press.

Clark, G. L., M. Fiaschetti and P. Gerrans (2014) The demand for advice in defined contribution pension plans: age, gender, and the size-of-bet effect, http://ssrn.com/abstract=2551819.

de Dreu, J. and J. A. Bikker (2012) 'Investor sophistication and risk taking', Journal of Banking and Finance, 36 (7) 2145-56. 
De Long, J. B., A. Shleifer, L. H. Summers and R. J. Waldmann (1989) 'The size and incidence of the losses from noise trading', Journal of Finance, 44 (3) 681-96.

Doran, J. S., D. Jiang and D. R. Peterson (2012) 'Gambling preference and the new year effect of assets with lottery features', Review of Finance, 16 (3) 685-731.

Foucault, T., D. Sraer and D. Thesmar (2011) 'Individual investors and volatility', Journal of Finance, 66 (4) 1369-1406.

Garrett, A. T. and S. Russell (1999) 'Gamblers favor skewness, not risk: Further evidence from United States' lottery games', Economics Letters, 63(1) 85-90.

Kirchler, E., B. Maciejovsky and M. Weber (2005) 'Framing effects, selective information, and market behaviour: an experimental analysis', Journal of Behavioral Finance, 6 (2) 90100.

Kumar, A. (2009) 'Who gambles in the stock market?', Journal of Finance, 64 (4) 1880-1933.

Laibson, D. (2003) 'Golden eggs and hyperbolic discounting', Quarterly Journal of Economics, $62,443-77$.

Linnet, J., A. Møller, E. Peterson, A. Gjedde and D. Doudet (2010) 'Dopamine release in ventral striatum during lowa gambling task performance is associated with increased excitement levels in pathological gambling', Addiction, 106 (2) 383-90.

Lusardi, A. and O.S. Mitchell (2011) 'Financial literacy around the world: an overview', Journal of Pension Economics and Finance, 10 (04) 497-508.

Mendel, B. and A. Shleifer (2012) 'Chasing noise', Journal of Financial Economics, 104, 30320.

Riba, J., U. M. Krämer, M. Heldmann, S. Richter and T. Münte (2008) 'Dopamine agonist increases risk-taking but blunts reward-related brain activity', PLoSOne, 3 (6) 1-5. 
Samuelson, W. A. and R. Zeckhauser (1988) 'Status quo bias in decision-making', Journal of Risk and Uncertainty, 1 (1) 7-59.

Scheinkman, J. A. (2014) Speculation, trading, and bubbles (Kenneth J. Arrow Lecture Series). New York: Columbia University Press.

Shiller, R. J. (2005) Irrational exuberance, 2nd edition, Princeton: Princeton University Press.

Shleifer, A. and L. H. Summers (1990) 'The noise trader approach to finance', Journal of Economic Perspectives, 4: 19-33.

Simon, H.A. (1956). 'Rational choice and the structure of the environment' Psychology Review 63: 129-138.

Song, S and J. Song, (2013) 'A note on the history of the gambler's ruin problem', Communications for Statistical Applications and Methods, 20(2) 157-168.

Stanovich, K. (2010) Decision-making and rationality in the modern world, Oxford: Oxford University Press.

Thaler, R. and Sunstein, C. (2008) Nudge: improving decisions about health, wealth and happiness, New Haven, CT: Yale University Press.

Tanabe, J., L. Thompson, E. Claus, M. Dalwani, K. Hutchinson and M. T. Manich (2007) 'Prefrontal cortex activity is reduced in gambling and non-gambling substance users during decision-making', Human Brain Mapping, 28 (12) 1276-86.

Weber, M., E. U. Weber and A. Nosic (2013) 'Who takes risks when and why: determinants of changes in investor risk taking', Review of Finance, 17 (3) 847-83.

Yu, R. and X. Zhou (2006) 'Brain responses to outcomes of one's own and others' performance in a gambling task', Cognitive Neuroscience and Neuropsychology, 17 (16) 1747-51. 


\section{Figures}

Figure 1 - Number of new active participants and stock market volatility (monthly): Macro-Scheme and Sample Scheme 'MMM'

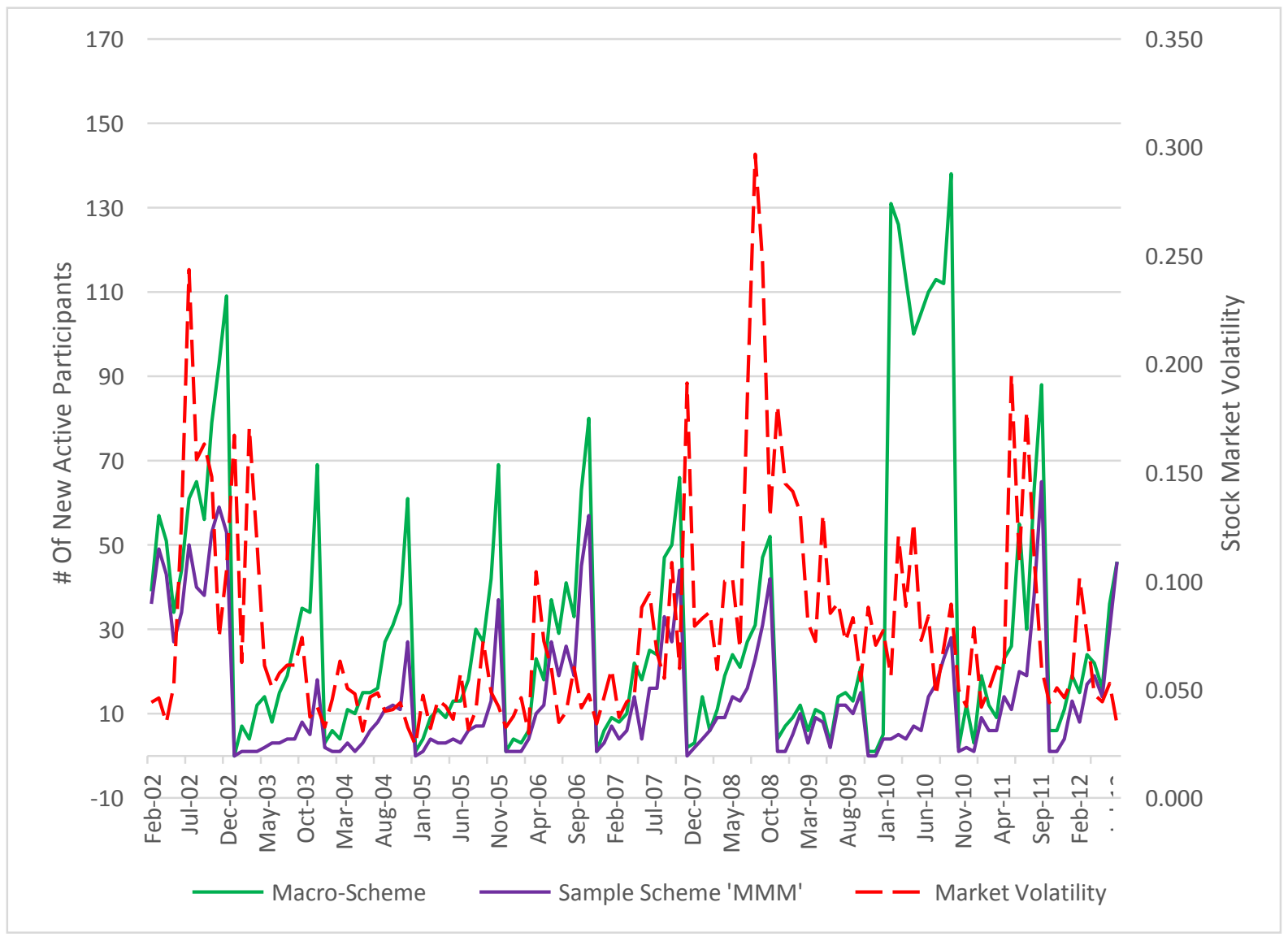




\section{Figure 2 - Multinomial logit analysis of participants' behaviour: interaction effects}
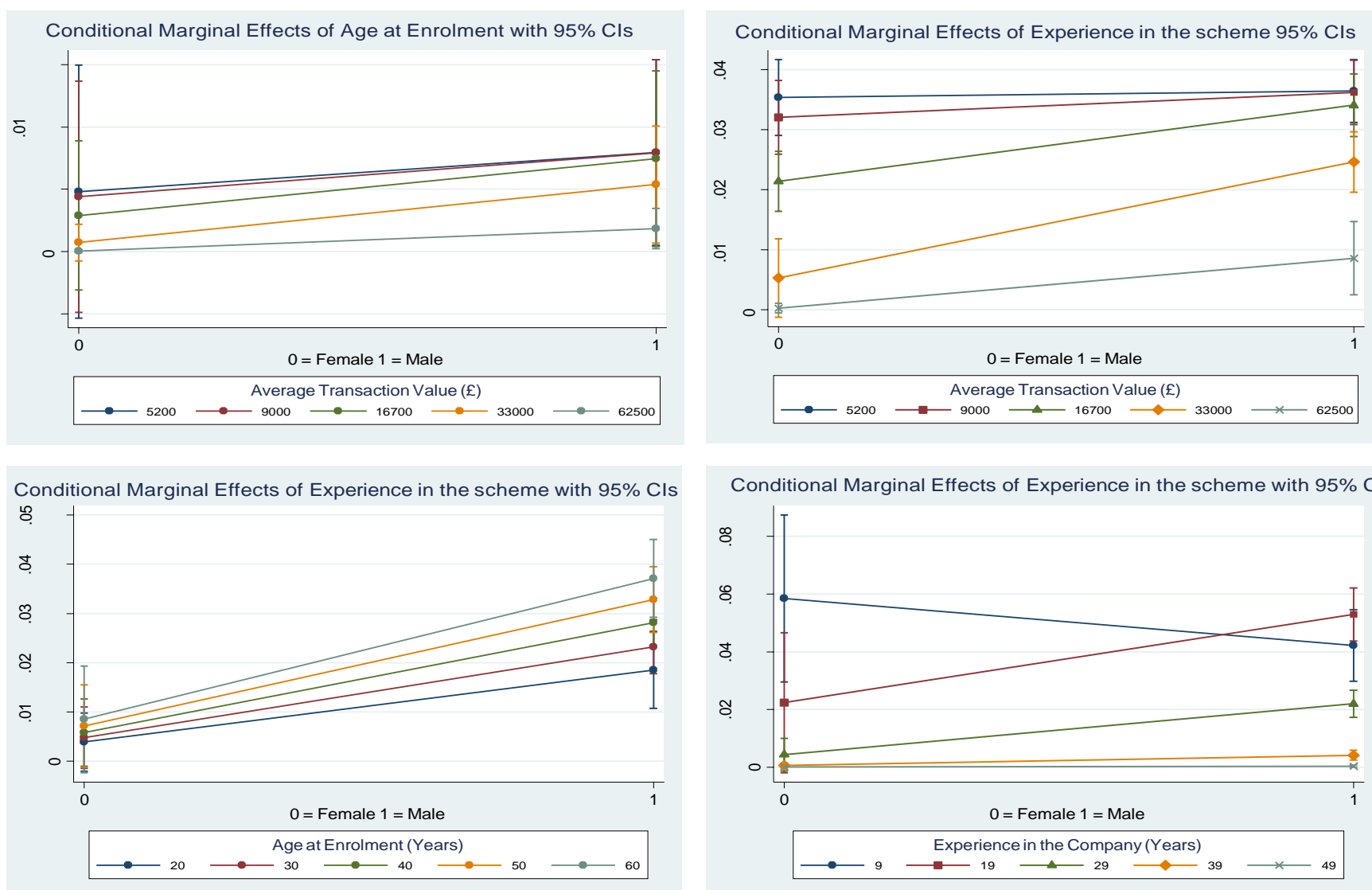
Tables

Table I - Composition of the schemes: number of transactions and participants (total number, active, inactive and by types)

a) - Number of participants across the schemes

\begin{tabular}{c|cc|cc}
\hline Scheme code & \multicolumn{2}{|c|}{ Transactions } & \multicolumn{2}{c}{ Participants (active and inactive) } \\
\hline \multirow{3}{*}{ BBB } & \# of transactions & \% of the total & $\begin{array}{c}\text { \# of individuals } \\
\text { in the scheme }\end{array}$ & \% of the total \\
\cline { 2 - 5 } CCC & 65,296 & 4.21 & 2,961 & 16.74 \\
DDD & 120,772 & 7.78 & 949 & 5.36 \\
EEE & 19,715 & 1.27 & 665 & 3.76 \\
GGG & 49,318 & 3.18 & 336 & 1.9 \\
HHH & 965 & 0.06 & 226 & 1.28 \\
III & 299,915 & 19.33 & 3,027 & 17.11 \\
KKK & 14,331 & 0.92 & 319 & 1.8 \\
LLL & 10,237 & 0.66 & 269 & 1.52 \\
MMM & 24,566 & 1.58 & 213 & 1.2 \\
\hline NNN & 326,316 & 21.03 & 3,368 & 19.04 \\
OOO & 14,599 & 0.94 & 108 & 0.61 \\
PPP & 133,396 & 8.6 & 577 & 3.26 \\
QQQ & 5,694 & 0.37 & 48 & 0.27 \\
RRR & 1,443 & 0.09 & 357 & 2.02 \\
SSS & 16,636 & 1.07 & 233 & 1.32 \\
TTT & 88,124 & 5.68 & 1,059 & 5.99 \\
YYY & 30,809 & 1.99 & 618 & 3.49 \\
ZZZ & 301,473 & 19.43 & 8324 & 8.62 \\
& 28,014 & 1.81 & 4.71 \\
\hline
\end{tabular}

b) - Number of participants making transactions across all the schemes (by type)

\begin{tabular}{|c|c|c|c|c|c|c|c|c|}
\hline \multirow{2}{*}{$\begin{array}{c}\text { Scheme } \\
\text { code }\end{array}$} & \multicolumn{2}{|c|}{ Gamblers } & \multicolumn{2}{|c|}{ Mixed Participants } & \multicolumn{2}{|c|}{ Quiet Participants } & \multirow{2}{*}{$\begin{array}{l}\text { Total active } \\
\text { participants }\end{array}$} & \multirow{2}{*}{$\begin{array}{l}\text { Total inactive } \\
\text { participants }\end{array}$} \\
\hline & $\begin{array}{c}\text { \# of } \\
\text { individuals }\end{array}$ & $\begin{array}{c}\% \text { of the } \\
\text { total }\end{array}$ & $\begin{array}{c}\text { \# of } \\
\text { individuals }\end{array}$ & $\begin{array}{c}\% \text { of the } \\
\text { total }\end{array}$ & $\begin{array}{c}\text { \# of } \\
\text { individuals }\end{array}$ & $\begin{array}{c}\% \text { of the } \\
\text { total }\end{array}$ & & \\
\hline BBB & 250 & 8.44 & 739 & 24.96 & 44 & 1.49 & 1,033 & 1,928 \\
\hline $\mathrm{CCC}$ & 227 & 23.92 & 683 & 71.97 & 33 & 3.48 & 943 & 6 \\
\hline DDD & 10 & 1.50 & 36 & 5.41 & 7 & 1.05 & 53 & 612 \\
\hline EEE & 82 & 24.40 & 249 & 74.11 & 4 & 1.19 & 335 & 1 \\
\hline GGG & 6 & 2.65 & 4 & 1.77 & 24 & 10.62 & 34 & 192 \\
\hline $\mathrm{HHH}$ & 234 & 7.73 & 883 & 29.17 & 51 & 1.68 & 1,168 & 1,859 \\
\hline III & 25 & 7.84 & 155 & 48.59 & 19 & 5.96 & 199 & 120 \\
\hline KKK & 27 & 10.04 & 52 & 19.33 & 2 & 0.74 & 81 & 188 \\
\hline LLL & 49 & 23.00 & 155 & 72.77 & 7 & 3.29 & 211 & 2 \\
\hline MMM & 387 & 11.49 & 1,239 & 36.79 & 367 & 10.90 & 1,993 & 1,375 \\
\hline NNN & 20 & 18.52 & 70 & 64.81 & 1 & 0.93 & 91 & 17 \\
\hline 000 & 29 & 5.03 & 152 & 26.34 & 9 & 1.56 & 190 & 387 \\
\hline PPP & 1 & 2.08 & 5 & 10.42 & 1 & 2.08 & 7 & 41 \\
\hline QQQ & 0 & 0.00 & 3 & 0.84 & 14 & 3.92 & 17 & 340 \\
\hline RRR & 0 & 0.00 & 39 & 16.74 & 1 & 0.43 & 40 & 193 \\
\hline SSS & 57 & 5.38 & 248 & 23.42 & 53 & 5.00 & 358 & 701 \\
\hline TTT & 56 & 9.06 & 85 & 13.75 & 55 & 8.90 & 196 & 422 \\
\hline YYY & 89 & 5.84 & 375 & 24.61 & 10 & 0.66 & 474 & 1,050 \\
\hline ZZZ & 2 & 0.24 & 58 & 6.96 & 30 & 3.60 & 90 & 743 \\
\hline
\end{tabular}


Table II - Descriptive statistics of the whole database and of the sample scheme 'MMM' a) - Descriptive statistics for the whole database

\begin{tabular}{|c|c|c|c|c|c|}
\hline Variable & Obs & Mean & Std. Dev. & Min & Max \\
\hline Female (\%) & 17689 & 38.32 & 0.49 & 2 & 3 \\
\hline Joining age (years) & 17176 & 35.31 & 10.48 & 16 & 69 \\
\hline Experience in the company (years) & 14783 & 7.13 & 9.39 & 0 & 48 \\
\hline Experience in the scheme (years) & 9415 & 22.07 & 14.43 & 0 & 61 \\
\hline Per capita transactions (\#) & 321484 & 783.91 & 610.92 & 1 & 4304 \\
\hline Average transaction value $(£)$ & 321484 & 13244.30 & 14783.70 & 0 & 1287355 \\
\hline $\begin{array}{l}\text { Average elapsed time between } \\
\text { consecutive transactions (months) }\end{array}$ & 317229 & 1.22 & 0.43 & 1 & 13.80 \\
\hline
\end{tabular}

b) - Descriptive statistics for the sample scheme 'MMM'

\begin{tabular}{|lccccc|}
\hline \multicolumn{1}{|c}{ Variable } & Obs & Mean & Std. Dev. & Min & Max \\
\hline & & & & & \\
Female (\%) & 3368 & 45.25 & 0.50 & 2 & 3 \\
Joining age (years) & 3001 & 30.99 & 8.25 & 16 & 0 \\
Experience in the company (years) & 2933 & 12.30 & 13.15 & 0 & 46 \\
Experience in the scheme (years) & 2207 & 28.90 & 10.05 & 1 & 49 \\
Per capita transactions (\#) & 78396 & 326.04 & 388.58 & 0 & 1302690 \\
Average transaction value (f) & 78396 & 24893.60 & 36464.63 & & 1 \\
Average elapsed time between & 76397 & 1.13 & 0.96 & & 29.00 \\
consecutive transactions (months) & & & & & \\
\hline
\end{tabular}


Table III - Correlation between participants making the first transaction and market volatility a) Pairwise correlation coefficients of the number of participants making their first transaction and market volatility (monthly) - Sample Scheme

\begin{tabular}{|c|c|c|c|c|c|c|c|c|}
\hline & $\begin{array}{l}\text { \# new active } \\
\text { participants }\end{array}$ & $\begin{array}{l}\text { Market } \\
\text { Volatility }\end{array}$ & $\begin{array}{c}\text { Market } \\
\text { volatiılty } \\
(\operatorname{lag} 1)\end{array}$ & $\begin{array}{l}\text { Market } \\
\text { Volatility } \\
(\operatorname{lag} 2)\end{array}$ & $\begin{array}{c}\text { Market } \\
\text { Volatility } \\
\text { (lag 3) }\end{array}$ & $\begin{array}{c}\text { Market } \\
\text { Volatility } \\
(\operatorname{lag} 4)\end{array}$ & $\begin{array}{c}\text { Market } \\
\text { Volatility } \\
\text { (lag 5) }\end{array}$ & $\begin{array}{c}\text { Market } \\
\text { Volatility } \\
\text { (lag 6) }\end{array}$ \\
\hline \multirow{3}{*}{ \# new active participants } & 1 & & & & & & & \\
\hline & 130 & & & & & & & \\
\hline & 0.1652 & 1 & & & & & & \\
\hline \multirow[t]{3}{*}{ Market Volatility } & 0.0613 & & & & & & & \\
\hline & 129 & 129 & & & & & & \\
\hline & $0.2711^{*}$ & $0.6059 *$ & 1 & & & & & \\
\hline \multirow[t]{3}{*}{ Market Volatility (lag 1) } & 0.002 & 0 & & & & & & \\
\hline & 128 & 128 & 128 & & & & & \\
\hline & $0.2656^{*}$ & $0.4893^{*}$ & $0.6048^{*}$ & 1 & & & & \\
\hline \multirow[t]{3}{*}{ Market Volatility (lag 2) } & 0.0025 & 0 & 0 & & & & & \\
\hline & 127 & 127 & 127 & 127 & & & & \\
\hline & 0.119 & $0.3674^{*}$ & $0.4869 *$ & $0.6038^{*}$ & 1 & & & \\
\hline \multirow[t]{3}{*}{ Market Volatility (lag 3) } & 0.1843 & 0 & 0 & 0 & & & & \\
\hline & 126 & 126 & 126 & 126 & 126 & & & \\
\hline & 0.0756 & $0.2450^{*}$ & $0.3647^{*}$ & $0.4855^{*}$ & $0.6024^{*}$ & 1 & & \\
\hline \multirow[t]{3}{*}{ Market Volatility (lag 4) } & 0.4021 & 0.0059 & 0 & 0 & 0 & & & \\
\hline & 125 & 125 & 125 & 125 & 125 & 125 & & \\
\hline & -0.036 & $0.2269 *$ & $0.2453^{*}$ & $0.3648^{*}$ & $0.4861^{*}$ & $0.6030^{*}$ & 1 & \\
\hline \multirow[t]{3}{*}{ Market Volatility (lag 5) } & 0.6916 & 0.0113 & 0.006 & 0 & 0 & 0 & & \\
\hline & 124 & 124 & 124 & 124 & 124 & 124 & 124 & \\
\hline & $-0.1853^{*}$ & $0.2702^{*}$ & $0.2312^{*}$ & $0.2478^{*}$ & $0.3684^{*}$ & $0.4897^{*}$ & $0.6038^{*}$ & 1 \\
\hline \multirow[t]{2}{*}{ Market Volatility (lag 6) } & 0.0402 & 0.0025 & 0.0101 & 0.0057 & 0 & 0 & 0 & \\
\hline & 123 & 123 & 123 & 123 & 123 & 123 & 123 & 123 \\
\hline
\end{tabular}

$* \mathrm{p}<0.10 * * \mathrm{p}<0.051 * * * \mathrm{p}<0.01$

b) - Simple OLS regression of the number of new active members and market volatility (monthly): Sample Scheme in red

\begin{tabular}{lcc|c|}
\cline { 3 - 4 } & $\begin{array}{c}\text { TOTAL } \\
\text { Sample }\end{array}$ & $\begin{array}{c}\text { Macro- } \\
\text { Scheme }\end{array}$ & $\begin{array}{c}\text { Scheme } \\
\text { MMM }\end{array}$ \\
\hline Market Volatility & 58.55 & 74.74 & 51.68 \\
& $(85.59)$ & $(57.98)$ & $(27.38)$ \\
Constant & & & $10.08^{* * *}$ \\
& $52.29 * * *$ & $25.36^{* * *}$ & $(2.511)$ \\
\hline Observations & $(7.852)$ & $(5.319)$ & \\
Adjusted R-squared & 129 & & 129 \\
& -0.004 & 0.005 & 0.020 \\
& & &
\end{tabular}

Standard errors in parentheses, * $p<0.05 * * p<0.01 * * * p<0.001$

Source: authors' calculation on Mercer's data 
Table IV - Principal Component Analysis - Eigenvalues and proportion of explained variation explained by each component

Whole database

Principal components

Number of obs

130

Number of comp.

3

Trace

3

Rotation: (unrotated $=$ principal)

Rho

1

\begin{tabular}{lcccc}
\hline Component & Eigenvalue & Difference & Proportion & Cumulative \\
\hline Gamblers & & & & \\
Mixed Participants & 1.6723 & 0.8721 & $55.74 \%$ & $55.74 \%$ \\
Quiet Participants & 0.8002 & 0.2726 & $26.67 \%$ & $82.42 \%$ \\
& 0.5275 &. & $17.58 \%$ & $100.00 \%$ \\
\hline
\end{tabular}

\section{Macro-Scheme}

Principal components

Number of obs

130

Number of comp.

Trace

3

Rotation: $($ unrotated $=$ principal)

Rho

1

\begin{tabular}{lcccc}
\hline Component & Eigenvalue & Difference & Proportion & Cumulative \\
\hline Gamblers & & & & \\
Mixed Participants & 1.8057 & 0.8655 & $60.19 \%$ & $60.19 \%$ \\
Quiet Participants & 0.9402 & 0.6861 & $31.34 \%$ & $91.53 \%$ \\
& 0.2541 &. & $8.47 \%$ & $100.00 \%$ \\
\hline
\end{tabular}

\section{Sample Scheme MMM}

\begin{tabular}{|c|c|c|c|c|}
\hline \multirow[t]{3}{*}{ Principal components/correlation } & Number of obs & 125 & & \\
\hline & Number of comp. & 3 & & \\
\hline & Trace & 3 & & \\
\hline Rotation: (unrotated = principal) & Rho & 1 & & \\
\hline Component & Eigenvalue & Difference & Proportion & Cumulative \\
\hline Gamblers & 1.6596 & 0.8536 & $55.32 \%$ & $55.32 \%$ \\
\hline Mixed Participants & 0.8061 & 0.2717 & $26.87 \%$ & $82.19 \%$ \\
\hline Quiet Participants & 0.5343 & . & $17.81 \%$ & $100.00 \%$ \\
\hline
\end{tabular}

Source: authors' calculation on Mercer's data 
Table V - Lagged market volatility and participants' type

a) Interquantile regression of the number of new active members and market volatility (monthly): Sample Scheme in red

\begin{tabular}{|c|c|c|c|}
\hline & $\begin{array}{l}\text { TOTAL } \\
\text { Sample }\end{array}$ & $\begin{array}{l}\text { Macro- } \\
\text { Scheme }\end{array}$ & $\begin{array}{c}\text { Scheme } \\
\text { MMM }\end{array}$ \\
\hline Lagged Market Volatility & $\begin{array}{l}88.78 \\
(1.65)\end{array}$ & $\begin{array}{l}-51.94 \\
(-0.48)\end{array}$ & $\begin{array}{c}88.78^{*} \\
(1.80)\end{array}$ \\
\hline Constant & $\begin{array}{c}21.47^{* *} \\
(2.83)\end{array}$ & $\begin{array}{c}50.56 * * * \\
(3.70)\end{array}$ & $\begin{array}{c}21.47^{* *} \\
(3.29)\end{array}$ \\
\hline Observations & 128 & 128 & 128 \\
\hline
\end{tabular}

Standard errors in parentheses, * $p<0.10 * * p<0.05 * * * p<0.001$

Source: authors' calculation on Mercer's data

b) Simple regression of the monthly number of new active members and market volatility (by participants' type) -: Sample Scheme in red

\begin{tabular}{|c|c|c|c|c|c|c|c|c|c|}
\hline \multirow[b]{3}{*}{ Lagged Market Volatility } & \multicolumn{3}{|c|}{ TOTAL Sample } & \multicolumn{3}{|c|}{ Macro-Scheme } & \multicolumn{3}{|c|}{ Scheme MMM } \\
\hline & Gamblers & \multicolumn{2}{|c|}{$\begin{array}{cc}\text { Mixed } & \text { Quiet } \\
\text { Participants } & \text { Participants }\end{array}$} & Gamblers & \multicolumn{2}{|c|}{$\begin{array}{cc}\text { Mixed } & \text { Quiet } \\
\text { Participants } & \text { Participants }\end{array}$} & \multicolumn{3}{|c|}{ Gamblers $\begin{array}{c}\text { Mixed } \\
\text { Participants Participants }\end{array}$} \\
\hline & $\begin{array}{l}13.17^{*} \\
(1.89)\end{array}$ & $\begin{array}{c}9.253^{* *} \\
(2.06)\end{array}$ & $\begin{array}{l}-6.271 \\
(-0.49)\end{array}$ & $\begin{array}{l}6.381 \\
(0.61)\end{array}$ & $\begin{array}{l}38.41 \\
(1.53)\end{array}$ & $\begin{array}{l}-7.596 \\
(-0.59)\end{array}$ & $\begin{array}{c}12.82^{*} \\
(1.76)\end{array}$ & $\begin{array}{l}6.135 \\
(1.37)\end{array}$ & $\begin{array}{l}-7.094 \\
(-0.55)\end{array}$ \\
\hline Constant & $\begin{array}{c}2.382 * * * \\
(3.72)\end{array}$ & $\begin{array}{c}8.744 * * * \\
(21.14)\end{array}$ & $\begin{array}{c}9.154 * * * \\
(7.84)\end{array}$ & $\begin{array}{c}6.440 * * * \\
(6.66)\end{array}$ & $\begin{array}{c}18.97 * * * \\
(8.22)\end{array}$ & $\begin{array}{c}10.25^{* * *} \\
(8.70)\end{array}$ & $\begin{array}{c}2.773 * * * \\
(4.13)\end{array}$ & $\begin{array}{c}9.550 * * * \\
(23.21)\end{array}$ & $\begin{array}{c}9.415^{* * *} \\
(7.95)\end{array}$ \\
\hline Observations & 128 & 128 & 128 & 128 & 128 & 128 & 128 & 128 & 128 \\
\hline Adjusted R-squared & 0.020 & 0.025 & -0.006 & -0.005 & 0.010 & -0.005 & 0.016 & 0.007 & -0.006 \\
\hline
\end{tabular}

Standard errors in parentheses, * $p<0.10 * * p<0.05 * * * p<0.001$

Source: authors' calculation on Mercer's data 
Table VI - Multinomial logit analysis of participants' behaviour: marginal effects

$$
\begin{aligned}
& \text { Change in Prob. Standard error [95\% Conf. Interval] } \\
& \text { [ }
\end{aligned}
$$

\begin{tabular}{lcccc}
\hline \multicolumn{4}{c}{ Predicted outcome: Dormant participant $(78.93 \%$ probability at mean values, $71.63 \%$ sample $)$} \\
\hline Age at enrolment & $-0.007732^{* * *}$ & 0.001976 & -0.011604 & -0.003859 \\
Male & $-0.165276^{* * *}$ & 0.035070 & -0.234013 & -0.096540 \\
Av. transaction value & $0.000008^{* * *}$ & 0.000001 & 0.000007 & 0.000009 \\
Exper. in the scheme & -0.003576 & 0.003406 & -0.010251 & 0.003100 \\
Exper. in the company & 0.0008956 & 0.003904 & -0.006756 & 0.008547 \\
Year & $V$ & $V$ & $V$ & $V$ \\
Fund ID & -0.0013369 & 0.000524 & -0.002364 & -0.000310 \\
\hline \multicolumn{1}{c}{ Predicted outcome: Low frequency and Few transactions $(0.02 \%$ probability at mean values, $2.82 \%$ sample) } \\
\hline Age at enrolment & 0.000001 & 0.000004 & -0.000007 & 0.000008 \\
Male & -0.000050 & 0.000092 & -0.000230 & 0.000130 \\
Av. transaction value & 0.000000 & 0.000000 & 0.000000 & 0.000000 \\
Exper. in the scheme & -0.000074 & 0.000085 & -0.000240 & 0.000091 \\
Exper. in the company & 0.000045 & 0.000053 & -0.000059 & 0.000149 \\
Year & $V$ & $V$ & $V$ & $V$ \\
Fund ID & -0.000007 & 0.000010 & -0.000026 & 0.000012 \\
\hline
\end{tabular}

\begin{tabular}{|c|c|c|c|c|}
\hline \multicolumn{5}{|c|}{ Predicted outcome: Low frequency and Many transactions (11.21\% probability at mean values, $3.30 \%$ sample) } \\
\hline Age at enrolment & 0.002157 & 0.001594 & -0.000968 & 0.005282 \\
\hline Male & -0.010735 & 0.014965 & -0.040065 & 0.018596 \\
\hline Av. transaction value & $0.0000012 * * *$ & 0.000000 & 0.000001 & 0.000002 \\
\hline Exper. in the scheme & $-0.010530 * * *$ & 0.001224 & -0.012929 & -0.008132 \\
\hline Exper. in the company & $0.012299 * * *$ & 0.001456 & 0.009445 & 0.015153 \\
\hline Year & $v$ & v & $v$ & $\checkmark$ \\
\hline Fund ID & $0.000884^{* *}$ & 0.000378 & 0.000143 & 0.001625 \\
\hline
\end{tabular}

\begin{tabular}{|c|c|c|c|c|}
\hline \multicolumn{5}{|c|}{ Predicted outcome: High frequency and Few transactions ( $0.006 \%$ probability at mean values, $10.75 \%$ sample) } \\
\hline Age at enrolment & 0.000007 & 0.000004 & -0.000002 & 0.000015 \\
\hline Male & $0.000298 * * *$ & 0.000071 & 0.000159 & 0.000438 \\
\hline Av. transaction value & $0.000000 * *$ & 0.000000 & 0.000000 & 0.000000 \\
\hline Exper. in the scheme & 0.000003 & 0.000002 & -0.000001 & 0.000007 \\
\hline Exper. in the company & -0.000001 & 0.000002 & -0.000004 & 0.000003 \\
\hline Year & $v$ & $v$ & 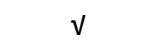 & $v$ \\
\hline Fund ID & 0.000000 & 0.000000 & 0.000000 & 0.000001 \\
\hline \multicolumn{5}{|c|}{ Predicted outcome: High frequency and Many transactions (9.83\% probability at mean values, $11.50 \%$ sample) } \\
\hline Age at enrolment & $0.001975^{*}$ & 0.001168 & -0.000315 & 0.004265 \\
\hline Male & $0.175763 * * *$ & 0.036014 & 0.105178 & 0.246348 \\
\hline Av. transaction value & $-0.000006 * * *$ & 0.000001 & -0.000007 & -0.000005 \\
\hline Exper. in the scheme & $0.012669 * * *$ & 0.003284 & 0.006232 & 0.019106 \\
\hline Exper. in the company & $-0.012903 * * *$ & 0.003658 & -0.020073 & -0.005732 \\
\hline Year & 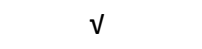 & 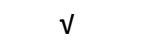 & 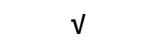 & 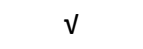 \\
\hline Fund ID & 0.000213 & 0.000375 & -0.000522 & 0.000947 \\
\hline
\end{tabular}

$* \mathrm{p}<0.10 * * \mathrm{p}<0.05 * * * \mathrm{p}<0.001$ 


\section{Appendix B: Gamblers' operations and market}

\section{trend}

This appendix provides a robustness check for the definition of gamblers, which is a central issue of the paper. We used information about the types of operations undertaken by the participants and the upside/downside trend of the financial market (FTSE100) to check for the consistency of the behaviour of those whom we labelled gamblers with that expected in the standard literature on gambling.

Given the structure of the database, we focused our attention on two characteristics the 'gambler's ruin' and the lack of diversification. According to the 'gambler's ruin', gamblers behave asymmetrically during winning and losing streaks, increasing (or at least failing to decrease) their commitment during the latter (see, among the others Song and Song 2013). Regarding the lack of diversification, and supplementing the cognitive literature on gambling, Garrett and Russell (1999) state that gamblers' attitude to risk is not the main driver of their action. Based on these results, in our database we checked the trading operations undertaken by those we labelled as 'gamblers' to find signs of an increased activity during the downtrend of the market (Hypothesis $A 1$, henceforth $\mathrm{H}-\mathrm{A} 1$ ) and of a scarce attention to the risk profiles of their operations (Hypothesis $A 2$, henceforth $H-A 2$ ).

To investigate $\mathrm{H}-\mathrm{A} 1$, we defined a 'downtrend' as a period of two (Definition 1 ) or alternatively three (Definition 2) consecutive months with a negative return of the FTSE 100 index and performed the analysis for both - the Macroscheme and the whole database. As shown in Table A.1, the number of downtrend months shrinks with the stricter Definition 2 (26 rather than 34 when Definition 1 is adopted). Looking at the Macroscheme, the average 
number of monthly transactions undertaken by gamblers increased during periods of downtrend ( +10.01 per cent and +4.44 per cent if we adopt the weaker Definition 1$)$. Results are also confirmed in the whole database, where transaction increased by 3.92 and 2.56 per cent respectively adopting Definitions 2 or 1 . The increased dynamism of gamblers during a period of negative returns confirms our expectations with respect to $\mathrm{H}-\mathrm{A} 1$.

Table A.1 Number of average per-month transactions

\begin{tabular}{|c|c|c|c|c|c|c|c|}
\hline & & \multirow{2}{*}{\multicolumn{3}{|c|}{ Macroscheme }} & & & \\
\hline & & & & & \multicolumn{3}{|c|}{ Total database } \\
\hline & Months & $\begin{array}{c}\text { Total } \\
\text { transactions }\end{array}$ & $\begin{array}{c}\text { Average } \\
\text { per-month } \\
\text { transactions }\end{array}$ & $\begin{array}{l}\text { Variation } \\
\text { during } \\
\text { downtrend }\end{array}$ & $\begin{array}{c}\text { Total } \\
\text { transactions }\end{array}$ & $\begin{array}{l}\text { Average } \\
\text { per-month } \\
\text { transactions }\end{array}$ & $\begin{array}{c}\text { Variation } \\
\text { during } \\
\text { downtrend }\end{array}$ \\
\hline & \multicolumn{7}{|c|}{ DEFINITION 1 ( Two consecutive months of negative return) } \\
\hline Uptrend & 95 & 293621 & 3091 & & 879368 & 9257 & \\
\hline \multirow[t]{2}{*}{ Downtrend } & 34 & 109750 & 3228 & $+4.44 \%$ & 322791 & 9494 & $+2.56 \%$ \\
\hline & \multicolumn{7}{|c|}{ DEFINITION 2 ( three consecutive months of negative return) } \\
\hline Uptrend & 103 & 315705 & 3065 & & 952347 & 9246 & \\
\hline Downtrend & 26 & 87666 & 3372 & $+10.01 \%$ & 249812 & 9608 & $+3.92 \%$ \\
\hline
\end{tabular}

Data Source: Authors' calculation and London Stock Exchange

To investigate $\mathrm{H}-\mathrm{A} 2$, we turned our attention to a subset of the database providing information about the types of operation undertaken by participants. An overall number of 152,497 trades were categorized into four types - switching between funds, quoting, partial selling and exit. We focused on switching for two reasons: it is the largest category $(51.59$ per cent vis-à-vis $25.38,22.47$ and 0.56 per cent respectively of exit, quote and partial selling) and it carries information about the participants' attitude to risk.

Unlike showing a preference to take and retake risky investment decisions time and time again, gamblers are supposed to disregard standard risk considerations among the drivers of their action and this is what we aimed to detect in our database. To this aim, we listed the 
funds available to the participants and classified them with respect to their asset allocation by adopting the following rule. We set up three categories of decreasing riskiness starting from the riskiest ('equity'), namely funds whose assets were more than 60 per cent in equity, a less risky 'balanced' category of funds investing between 40 and 60 per cent in equities and the safest 'not-equity' whose funds have less than 40 per cent of equity assets. Out of a total number of 293 funds, equity represented 55.78 per cent of the available choices, balanced 10.54 per cent and not-equity 33.67. We then turned our attention to the risk profile of each switching operation coming from gamblers and analysed the difference between the asset class of the old (left) fund and that of the new (entered) one. Due to the structure and characteristics of the database, we concentrated on the representative scheme MMM only and Table A.2 shows the results of the analysis. The steps of increase/decrease measure the difference in the risky category between the old and new fund in any operation. Consequently, a one-step increase could mean an operation of switching from a fund in the balanced category to one in equity. A two-step decrease, instead, could mean switching from a fund in equity to one in not-equity. As shown, the vast majority of the switching trades were between two funds in the same risk category $(44.83$ per cent), thus signalling that, when acting, gamblers were scarcely concerned about rebalancing their portfolios with respect to risk categories of asset allocation. This confirms our hypothesis $\mathrm{H}-\mathrm{A} 2$.

Table A.2 Riskiness of the switching operations from gamblers

\begin{tabular}{c|ccccc|} 
& \multicolumn{5}{c}{ Representative scheme MMM } \\
\cline { 2 - 6 } & $\begin{array}{l}\text { Two-step } \\
\text { decreased } \\
\text { riskiness }\end{array}$ & $\begin{array}{l}\text { One-step } \\
\text { decreased } \\
\text { riskiness }\end{array}$ & $\begin{array}{l}\text { Same risk } \\
\text { category }\end{array}$ & $\begin{array}{l}\text { Two-step } \\
\text { increased } \\
\text { riskiness }\end{array}$ & $\begin{array}{l}\text { One-step } \\
\text { increased } \\
\text { riskiness }\end{array}$ \\
\cline { 2 - 6 } $\begin{array}{c}\text { Share of switching } \\
\text { operations }\end{array}$ & $18.69 \%$ & $8.40 \%$ & $44.83 \%$ & $10.44 \%$ & $17.64 \%$ \\
\hline
\end{tabular}


Data Source: Authors' calculation

The final step was to match together the information about the type of operations undertake by gamblers and market trends. To show a consistent gambling behaviour, the agents we defined as such were supposed to increase their action in periods of downtrend, irrespectively of considerations about risk in asset allocation. We performed the analysis on the representative $\mathrm{MMM}$ scheme only with respect to switching operations between funds in the same risk category and Table A.3 shows the results.

Table A.3 Frequency analysis of switching operations between funds in the same risk category from gamblers during periods of market up/down trend

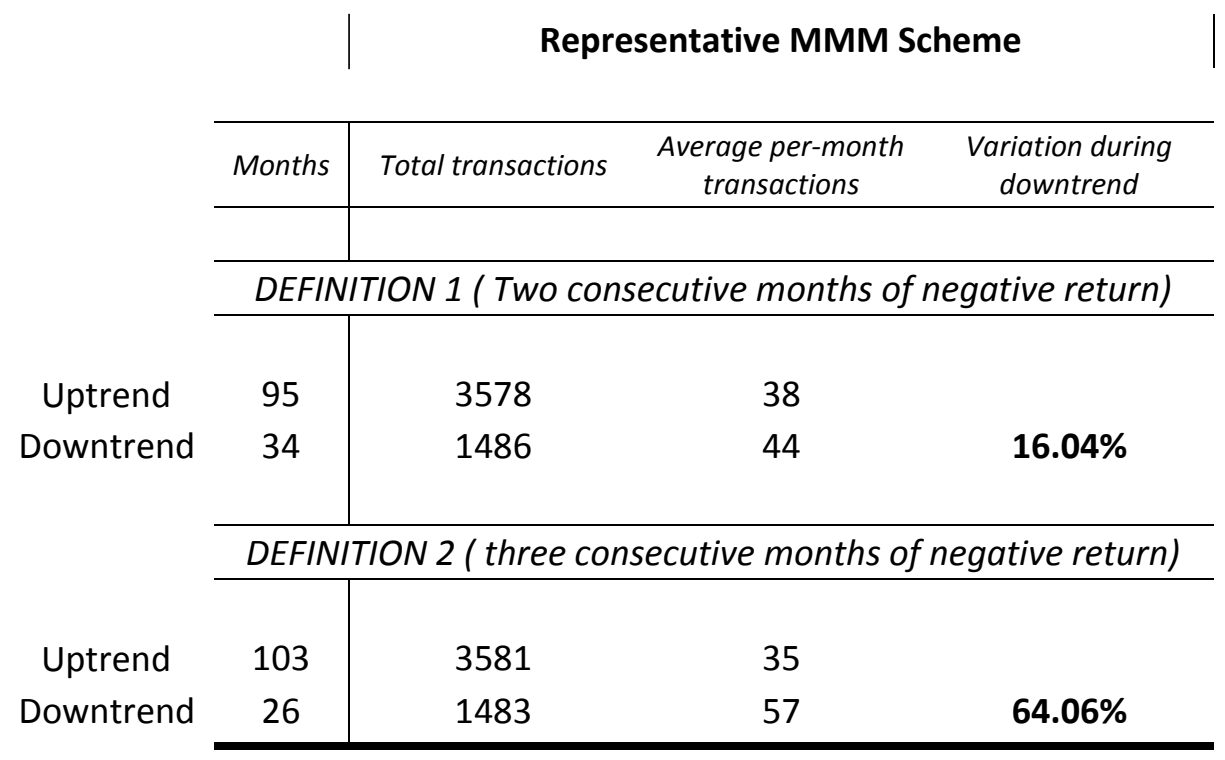

Data Source: Authors' calculation

Once again, our expectations were met in that we detected an even larger order of magnitude in the increase of the activity. The encouraging results confirmed the robustness of our classification defining gamblers. 